\title{
Reconstructing School Chemistry Curriculum in the Era of Core Competencies: A Case from China
}

\author{
Bing Wei \\ Faculty of Education, University of Macau \\ Room 3027, E33, Avenida da Universidade, Taipa, Macau, P. R. China
}

\begin{abstract}
In China, the new Senior High School Chemistry Curriculum (SHSCC) has been developed in the era of core competencies as response to social changes. This paper provides an account of the official document of this curriculum, the Chemistry Curriculum Standards of Senior High School (the 2017 version) with the aim of examining the mechanism of embedding the notion of core competencies in the new chemistry curriculum. An internalist perspective was adopted to analyze its process and product. Data were mainly collected from two sources: curriculum documents related with the new SHSCC and interviews with two key informants who were involved in designing the new curriculum. A narrative analysis was conducted to produce five themes, they are: (1) social context; (2) sources; and (3) conceptualization of chemistry core competencies; (4) structure and content; and (5) teaching requirements. In the last part of this article, the discussion is focused on three issues: (1) the curriculum idea and discourses in the view of core competence; $(2)$ the construction of subject matter of chemistry in the internalist views; and (3) the globalization and localization of chemistry curriculum.
\end{abstract}

KeyWords: Chemistry Curriculum; Core Competencies; Curriculum Change; Senior High School 


\section{Introduction}

As part of science education, school chemistry plays a critical role in both preparing learners for a further training as professional chemists and educating students to become qualified citizenry in the future. The structure and content of school chemistry curriculum have always been constructed and reconstructed to respond to social needs in the history (De Vos, Bulte, \& Pilot, 2002). During recent decades, there is a global consensus that international competition in the future is the talent competition; therefore, redefining the talent for the twenty first century and adjusting school education to suit the new definition have become priorities in education development. Since the turn of the century, some international organizations and institutes, such as the Organization for Economic Cooperation and Development (OECD) (Ananiadou \& Claro, 2009), the European Union (EU, 2008), have established a far-reaching core competence framework from both theoretical and practical aspects. The introduction of the conceptual framework of core competencies has had a tremendous impact on school curriculum reform of many countries around the world. The existing literature is filled with position papers and reviewing studies on the influences of core/key/21st-century competencies on curriculum frameworks (Voogt \& Roblin, 2012) but few studies have been done to investigate the embodiment of the notion of core competencies in school science/chemistry curricula.

In order to get along the international tendency of the world, the central government of China has initiated the latest round of curriculum reform with the notion of core competencies as a key theme (Yao \& Guo, 2018). The ambition of this reform is to raise the quality of education in order for students to meet the challenges of new times and propel curriculum reform into a high-quality development stage, and achieve higher goals of improving the overall quality of education (MoE, 2018). Thus, the notion of core competencies has been used as an impetus to design subject-based school curricula, including the SHSCC reported in this article. In China, the centralized curriculum system is adopted, that is, the Ministry of Education (MoE), the top educational administration, has the highest authority in planning and designing the school curriculum. For each subject, the national curriculum standards function as the "basis of compiling textbooks, practical teaching, teaching evaluation and examinations" in the teaching and learning of this subject (MoE, 2001 , p. 4). The new SHSCC, marked by the release of the Chemistry Curriculum Standards of Senior High School (the 2017 version) (called the 2017 curriculum standards for brevity) by the MoE in January 2018 (MoE, 2018) has provided a case for us to explore the issue of embodying core competencies in chemistry curriculum in a given social context. In this study, I attempted to deconstruct the process of designing the 2017 curriculum standards with the focus on three research questions: (1) what was the genesis of the new SHSCC? (2) how has the notion of core competencies been conceptualized in the new SHSCC; and (3) in what way is the notion of core competencies manifested in the new SHSCC? 


\section{Theoretical Perspective}

Curriculum change may be informed and determined by a range of influences and events, which operate at either macro or micro or both levels in society (Goodson, 1993). First of all, school curriculum is inextricably linked to social context. Therefore, historical, cultural, economic, and political forces in a society are interrelated to form and shape school science curricula. For school subjects, it is correct to view them as social, political, and historical constructions yet it is difficult to reveal and clarify the issues intrinsic to the school subjects themselves, including the organization and formulation of the subject matter within them in the macro view (Deng, 2007). The subject matter knowledge has long been concerned by many scholars since it is the subject matter that can render meaningful and educative experiences to students. In the field of teacher education, for instance, Shulman and his associates conceptualize teachers' subject matter knowledge in terms of content knowledge, pedagogical content knowledge (PCK), and curricular knowledge (Shulman, 1987). Later on, Grossman, Wilson, and Shulman (1989) further proposed that content knowledge should consist of the following four components: (1) content knowledge - the "stuff" of a discipline; (2) substantive knowledge - knowledge of the explanatory framework or paradigms of a discipline; (3) syntactic knowledge - knowledge of the ways in which new knowledge is generated in a discipline; and (4) beliefs about the subject matter - feelings and orientations toward the subject matter. As analyzed by Deng (2007), logical, psychological, pedagogical, epistemological, and sociocultural issues are often involved in the process of constructing the subject matter of a secondary school subject. Therefore, exploring these issues requires the so-called 'internalist perspective' - a perspective that examines the subject matter of a school subject in its own right, construing it as having intrinsic epistemological and educational values (Moore, 2000). In order to understand how subject curricula change over time, Goodson (1993) has suggested that "we need to understand how subject groups take up and promote new ideas and opportunities" (p. 4). As far as a science subject is concerned, there are three groups of people "within the subject", scientists, science teachers, and science educators (Fensham, 1997). In China, science teacher educators, or chemistry teacher educators in this study, have become a dominant group and play a critical role in chemistry curriculum development and chemistry teacher education (both pre-service and in-service) (Wei, 2012). Based on these theoretical foundations, this study was aimed to explore the mechanism of embedding the notion of core competence in the 2017 curriculum standards in the view of curriculum designers, a professional group of chemistry teacher educators in China.

\section{Methodology}

In order to provide reasonable answers to the research questions, data were collected from two sources: curriculum documents related with the new SHSCC and interviews with key informants involved in designing the 2017 curriculum standards. Curriculum documents mainly fell in four categories: (1) the 2017 curriculum standards (MoE, 2018); (2) national educational and curriculum policies related to chemistry curricula; ( 3 ) the illustrations to the 2017 curriculum standards provided by the curriculum designers (such as, Fang \& Xu, 2018; 
Wang \& Wei, 2018); and (4) discussions, debates, or suggestions concerning science/chemistry curricula within or beyond the chemistry education community in China. Documents were collected and analyzed prior to the interviews. In this study, two key informants were interviewed for clarifying and disclosing the inside story behind the 2017 curriculum standards. Both of them were involved in the process of designing the new SHSCC with one only participating in the early work and the other in the whole process. An approximately 50 minute interview was conducted with each of them. During the interview, two types of interview questions were asked. The first was "descriptive questions", which centered on the basic facts about the genesis of the 2017 SHSCC. The second was "exploratory questions". They usually arose from document analyses or preliminary analysis of the interviews that had been conducted before.

Data analysis was focused on the product and process the 2017 SHSCC. Given that this is a qualitative study in its nature, themes were generated from empirical data; however, the existing literature concerning the dimensions and theories of science curriculum development in general and subject-based curriculum development in particular was also taken into account when the encoding work was conducted (Charmaz, 2006). While analyzing the 2017 curriculum standards, the "curriculum proper" (Posner, 1995, p. 69), that is, the goal, structure, content, and expectations were highlighted with special attention given to the rationale, dimensions, and contents of chemistry core competencies. The interviews, together with the various documents, were analyzed to capture national educational and curriculum policies related to the SHSCC. Moreover, the analysis was done on curriculum designers' viewpoints and propositions on the nature of chemistry and the educational values of chemistry curriculum. Finally, five themes related to the process and product of the 2017 SHSCC emerged from a variety of data, they are: (1) Social context; (2) Sources; (3) Chemistry core competencies; (4) Structure and content; and (5) Teaching requirements. In the section that follows, these five themes will be explicated in turn on the basis of the analytical framework (Table 1).

Table 1: The analytical framework

\begin{tabular}{|c|c|c|}
\hline Themes & Analytical focuses & Data sources \\
\hline - Social context & $\begin{array}{l}\text { - National educational policies; } \\
\text { The notion of "lide suren"; } \\
\text { Core competency framework. } \\
\text { - Recognized nature of } \\
\text { chemistry; Recognized } \\
\text { tendency of chemistry } \\
\text { curriculum development. } \\
\text { - The rationale; Dimensions; } \\
\text { Contents. }\end{array}$ & $\begin{array}{l}\text { (1) The } 2017 \text { curriculum } \\
\text { standards; } \\
\text { (2) National educational } \\
\text { and curriculum policies } \\
\text { related to chemistry } \\
\text { curricula; } \\
\text { (3) The illustrations to the } \\
2017 \text { curriculum standards; }\end{array}$ \\
\hline
\end{tabular}


- Chemistry core competencies

- Structure and content

- Teaching requirement
- Required/selective courses; Topics/Modules/Series.

- Assumed roles; Relationship with teaching content.
(4) Discussions, debates, or suggestions;

(5) Interviews with two key informants.

\section{Results}

\subsection{Social context}

Influenced by Confucianism, Chinese people and government used to be content with the situation that a vast society was overseen by a small group of the elite but China has recently become aware that a mass education model should be adopted to replace the traditional elite-oriented education system (Liang, Liu, \& Fulmer, 2017). Since the late 1990s, the central government of China has adopted a national strategy, called "invigorating China through science and education". It was the political background of initiating quality education in general and chemistry curriculum reform in particular, which featured the notion of "scientific literacy" as the central theme at the beginning of the new millennium (Wei, 2005). In recent years, the soaring economy in China has brought tremendous changes in social development and personal lives, and prompted the government to look for strategies to sustain long-term development of the country. In 2010, the central government of China established the national mid- and long-term educational reform and development planning outline (20102020), in which "carrying out in-depth research to determine the core content that students in different educational stages should master" and "promoting curriculum reform and strengthening teaching and learning material development" were advocated as two major tasks during the period of 2010-2020 for educational development (Central Committee of the Communist Party of China \& State Council, 2010). At the 18th National Congress of the Communist Party of China, the notion of lide suren was advocated as the fundamental mission of education in China (Yao \& Guo, 2018). By the term lide suren, it means that, the core idea of educational development is to foster integrity and promote all-round development of people with a special focus on cultivating in students' sense of social responsibility, the spirit of innovation and the ability to acquire practical abilities. To implement the core idea, the opinions on deepening curriculum reform and implementing the fundamental tasks of lide shuren was promulgated by (MoE, 2014).

\subsection{Sources}

According to the designers of the 2017 curriculum standards, the genesis of the national standards of curriculum mainly came from two sources (Wang, 2018a). The first source was the criticism on the then existing SHSCC. In China's last round of curriculum reform, in 
accordance with the overall requirements of curriculum reform, the curriculum objectives of all subjects were arranged into the three dimensional goal system: scientific knowledge and skills, process and methods, and attitudes and values (MoE, 2001). Within this common framework, chemistry curriculum was constructed by the notion of scientific literacy in terms of its content and goals (Wei, 2005; Wei \& Thomas, 2005). As thought by the designers of the 2017 curriculum standards, the three-dimensional framework could be applied to all school subjects and thus it was too broad and was unable to reflect the feature of chemistry as a school subject (Wang, 2018a). Instead, the core competency framework mentioned above was thought to be helpful to reconstruct the SHSCC by breaking the three-dimensional goal system.

In the stage of preparatory work, the team of the project conducted a lot of library work in search of the statements about the nature of chemistry through both Chinese and English literature. Based on various discourses on chemistry, they finally made the following definitions of chemistry:

- Chemistry is focused on the properties and changes of substances; and it is purported to investigate regular patterns of chemical reactions via examining the compositions and structures of substances;

- Chemistry is merited with wide applications in society; chemists produce new substances by making use of mutual transformations among substances so as to serve human civilization and social progress; and

- Chemical research starts at macro-phenomena and then goes to micro-levels, using chemical symbols to describe properties and changes of substances.

(Wang, 2018b, p. 52)

The other source of the new SHSCC came from chemistry curriculum development in other countries around the world. Prior to designing the 2017 curriculum standards, the designers had conducted a comparative project, in which they extensively read varied kinds of chemistry programs, chemistry/science curriculum standards or frameworks imported from foreign countries (Wang, 2014). Unlike in designing the 2003 curriculum standards, for which references were almost focused on chemistry curriculum materials imported from English speaking countries; this time, references were also made to those from non-English speaking countries, such as Russia, Israel, India, and Japan. The characteristics of chemistry curriculum development at the sage of the senior high school during the past ten years were summarized as follows:

- The emphases have been put on the big ideas and key concepts of chemistry and the embodiment of the nature of chemistry as well;

- The basic methods and modes of chemistry learning and research, and the competencies of chemistry as a subject have been highlighted, such as experimental investigation, micro-presentation, trans-disciplinary integration, modelling thinking, dialectical thinking, independent thinking, and critical and innovative thinking; and 
- Much more concerns have been given to social values of chemistry, such as the impact of chemistry on daily lives, environmental protection, health and nutrition, technological application, and social responsibility.

(Wang, 2018b, p. 54)

\subsection{Chemistry core competencies}

Under the unified deployment of $\mathrm{MoE}$, as recalled by key informants, the first task of the design team was to define chemistry core competencies as the essential characteristics and key abilities that students need to acquire through chemistry education to ensure lifelong development and social progress. Based on the preparatory work, the designers thought that chemistry core competencies should reflect these features: (1) the distinctive characteristics of chemistry; (2) the social values of chemistry; and (3) the latest research achievement on chemistry/science teaching and learning. After several discussions and debates, the framework of chemistry core competencies was proposed, which included five dimensions: (1) macroscopic identification and microscopic analysis; (2) changes and equilibrium; (3) evidence-based reasoning and modelling; (4) scientific inquiry and innovation; and (5) scientific attitude and social responsibility.

\subsection{Structure and content}

The SHSCC is defined as an introductory subject-based curriculum for general education (referring to 1-12 grades in the Chinese education system), preceded by junior high school chemistry curriculum, which is offered in the ninth grade (the last year of compulsory education) (MoE, 2018). The importance of the SHSCC in general education is argued in the following aspects: (1) to achieve the fundamental mission of lide suren; (2) to raise the level of students' core competencies; and (3) to play an irreplaceable role in disseminating scientific knowledge and cultivate scientific and technological talents with high quality (MoE, 2018). In the stage of senior high school in China, like other parts in the world, students' needs become very diversified - some will be studying in the science stream while others will choose to study in the stream of arts and human. Therefore, multiple options of the SHSCC are necessary. In the 2003 SHSCC, there were two types of courses, compulsory courses, including chemistry 1 and chemistry 2, and six selective courses (Wei, 2005). To make more space for student to choose, the new SHSCC is composed of three types of courses, they are: (1) required; (2) optional required; and (3) selective. According to the designers, the required is for all students to develop basic chemistry core competencies while the optional required is for students who need to sit in the college admission examination to further develop chemistry core competencies, and the selective is for students to take freely with the emphasis on the social values of chemistry (MoE, 2018). The elements of these courses are different, i.e. so-called "Topics", "Modules" and "Series". The require course contains five Topics (4 credits): (1) chemical science and experimental inquiry; (2) common inorganic substances and their application; (3) structure of substances and chemical reactions; (4) 
simple organic compounds and their application; and (5) chemistry and social development. The optional required is composed of three modules with each model being given 2 credits, they are: (1) principles of chemical reactions; (2) structure and property of substances; (3) basics of organic chemistry. Students can select one model ( 2 credits), two models ( 4 credits) or three models (6 credits). Three series are provided for the selective: (1) experimental chemistry; (2) chemistry and society; and (3) chemistry in development.

\subsection{Teaching requirements}

Traditionally, the school curriculum in China was focused on knowledge points to be taught and school teachers were responsible for defining teaching content and establishing teaching requirements in practice. In this curriculum system, teachers were treated as active professionals, and only provided with guidelines for teaching; they themselves select the content and construct a meaningful curriculum for their students. In reality, however, teaching requirements were often steered by high-stake examinations, such as national (or provincial) college admission examination, usually called gaokao. More often than not, teaching requirements were overly elevated to cater for the needs of those external examinations, leading to students' heavy overload in study. In recent decades, influenced by standards-based curriculum reforms (DeBoer, 2011), the Chinese curriculum system is more closely aligned with the American curriculum tradition, in which teachers are requested to follow precise checklists that describe students' expected outcomes (Wang, Lavonen, \& Tirri, 2018). This is the reason that students' learning outcomes have been gradually emphasized in the chemistry curriculum of China. Specifically, based on the international comparative study on science/chemistry curriculum documents, it was learned that "performance standards are descriptions of students' learning levels... and will finally drive the fundamental change of chemistry education via curriculum evaluation" (Wang, 2014, p. 6). In the 2017 curriculum standards, both traditional practice highlighting the subject content knowledge and desired outcomes-based practice have been adopted. That is to say, curriculum content is presented in "content requirements" for school chemistry teachers' easy understanding of what to be taught (scope and breadth), whilst "performance requirements" are prescribed to define the depth of the curriculum content (Wang \& Wei, 2018). As recalled by key informants, a consensus was achieved among the designing team that this practice would be beneficial to fully implement the five dimensions of chemistry core competencies in practice.

\section{Discussion}

This paper has provided an account of the recently released senior high school chemistry curriculum in China, which claims to be based on the notion of core competencies. In examining the mechanism of embedding the notion of core competencies in chemistry curriculum, an 'internalist perspective' was adopted to analyzing the process and product of the 2017 curriculum standards of the SHSCC, which were reflected in the five themes: (1) social context; (2) sources; and (3) chemistry core competencies; (4) structure and content; 
and (5) teaching requirements. As a single case, the findings of this study are limited because they cannot be generalized beyond the context of this study. However, the results of this study will provide implications for the theories and practices of embedding the notion of core competencies into the subject-based curricula in other parts of the world. More significantly, the findings of this study might be transferable to other social contexts because it has addressed some issues that will occur in other countries especially developing countries when designing a science/chemistry curriculum in the era of core competencies. In the rest of this section, I will discuss these issues in turn.

\subsection{The curriculum idea and discourses in the view of core competencies}

To a certain extent, curriculum is made by human beings, and curriculum making operates across different levels, each of which is linked to a distinct kind of curriculum discourse. There are three "levels" of such discourse, as noted by Deng (2011), encompassing institutional discourse, programmatic discourse, and classroom discourse. Similar to the notion of scientific literacy mentioned in Deng's (2011) article, the notion of core competencies is a slogan, signifying the attributes and capacities that need to be cultivated for all students in the age of globalization. Coincidentally, the notion of core competencies is aligned with the core idea of educational development advocated by the central government of China. This was the reason that the notion of core competencies was unanimously accepted by the academics and the government and had become the institutional discourse in this round of curriculum reform in this country. As a socially constructed notion, the content of the core competencies of the new generation would be determined by economic, political, cultural factors in a given social context like China. These various kinds of factors have constituted the social background of the framework of core competencies established by the Research Group (2016). However, this general and broad framework is not able to play a substantially influential role on school curriculum and instruction until it is translated into individual subject-based curricula like the SHSCC reported in this study. As shown in this study, the conceptualization of chemistry core competencies has not only been determined by the core competency framework but also by the internal issues of a subject, such as logical, psychological, pedagogical, epistemological, and sociocultural issues (Deng, 2007). In addition, the national chemistry curriculum standards in China is a unique discourse of subject-based school curriculum, comprising of regular constituents, such as curriculum ideas, curriculum goals, curriculum contents, and instructional suggestions. For the case of the SHSCC, the five dimensions of the chemistry core competencies and their embodiments in the structure, content and teaching requirements of the SHSCC have constituted the programmatic discourses of core competencies.

\subsection{The construction of subject matter of chemistry in the internalist views}

According to Grossman and Stodolsky (1994), secondary school subjects are independent entities because they have "their own histories, pedagogical traditions, and status within high 
schools" (p.182), constituting the "locus" of secondary school teaching, framing classroom teachers' practice and perspectives on curriculum and instruction, and affecting how they interpret and respond to educational policies (Grossman \& Stodolsky, 1995). The relationship between academic disciplines and school subjects is controversial (Stengel, 1997) but most scholars believe that academic discipline is used to provide the frame of reference for defining and delineating what classroom teachers need to know about the subject matter they are supposed to teach (Deng, 2007). However, this study has challenged this viewpoint. As mentioned earlier, in China, chemistry teacher educators from normal universities as an emergent professional group have played an increasingly important role in pre-service and in-service chemistry education, curriculum development, and textbook compilations. Some of them, usually coming from national key normal universities in China, have participated in the process of designing the new SHSCC under the coordination of the Ministry of Education. They are familiar with the national education and curriculum policies and have various channels of connecting with chemistry teachers of high schools. More importantly, they have been informed of academic scholarship recently advanced in the international community of science education, such as nature of science, socio issues, science practices, scientific reasoning. Therefore, those five themes of chemistry core competencies can be seen as the newly constructed subject matter of chemistry. Specifically, the two themes, "macroscopic identification and microscopic analysis" and "changes and equilibrium", reflect their own understanding of the nature of chemistry. Other two themes, "evidence-based reasoning and modelling" and "scientific inquiry and innovation" were mainly input from the international community of chemistry education in particular and science education in general. For the last theme, "scientific attitude and social responsibility", it is mainly a response to the national education mission, lide suren. As agents of national curriculum policies and teacher educators in university, chemistry teacher educators in China made the translation of ideas of curriculum reforms into classroom practices seamlessly (Wei, 2012). In this study, it has been found that practical knowledge they obtained from teaching practice was reflected in the national curriculum standards. For example, "Tips for instructions" were essentially school chemistry teachers' practical knowledge and had been obtained from teaching practice. Obviously, this two-way interaction between "theory" and "practice" is helpful to avoid the disconnection among policy-makers, educational researchers, and practitioners in the enterprise of chemistry education.

\subsection{The globalization and localization of chemistry curriculum}

Nowadays, all parts of the global society are so interconnected that chemistry curriculum development in an individual country is possibly influencing and influenced by that occurring in other countries. Since the late 1970s, especially joining the World Trade Organization (WTO) in 2001 and implementing the national policy of "one belt and one road", which was initiated in 2013, China has gradually become an important member of the global community, therefore inevitably involved in competition and cooperation with other nations across the world. However, in terms of its characteristics in the education system and social and cultural backgrounds, China is distinctive from many other nations in the planet. Therefore, the 
reconstruction of the SHSCC should take into account the reality, the future development and teaching traditions of China. Furthermore, as China is a developing country, science curriculum in general and chemistry curriculum in particular in this country has to face the influences from the West. In the last round of school curriculum reform in China, for instance, school chemistry curriculum took scientific literacy as the central theme (Wei, 2005; Wei \& Thomas, 2005). In the current curriculum reform, the notion of core competencies has been borrowed from the international community of education (Ananiadou \& Claro, 2009; Pepper, 20111; EU, 2008) and is used to reconstruct the new SHSCC, which involves the issue of the balance between globalization and localization. As Stacey et al (2018) indicated, the globalization of science curricula has been driven by a variety of forces. Carter (2005) further argued that the "current science education improvement discourses are more representative of national responses to global economic restructuring and the imperatives of the supranational institutions than they are of quality research into science teaching and learning" (p. 573). Therefore, attention should be drawn to the problem of how to deal with the influences and impacts from the developed on the developing countries so as to produce "authentic, contextually, and affordable (science curriculum)" (Gray, 1999, p. 262). In this sense, the new SHSCC has provided an exemplary case for developing countries in dealing with the issue of the balance between globalization and localization of chemistry curriculum.

\section{Reference}

Ananiadou, K., \& Claro, M. (2009). 21st century skills and competencies for new millennium learners in OECD countries. OECD Education working papers. https://doi.org/10.1787/218525261154

Carter, L. (2005). Globalization and science education: rethinking science education reforms. Journal of Research in Science Teaching, 42, 561-580.

Central Committee of the Communist Party of China \& State Council (2010). The outline of the national mid- and long-term plan for educational reform and development (20102020). Official document (In Chinese).

Charmaz, K. (2006). Constructing grounded theory: A practical guide through qualitative analysis. London: Sage Publications.

DeBoer, G. E. (2011). The globalization of science education. Journal of Research in Science Teaching, 48 (6), 567-591.

Deng, Z. (2007). Knowing the subject matter of a secondary-school science subject. Journal of Curriculum Studies, 39 (5), 503-535.

Deng, Z. (2011). Scientific literacy: Content and curriculum making. In: C. Linder, Östman, L., Roberts, A., D., Wickman, P., \& Erickson, G., \& MacKinnon (Eds.), Exploring the landscape of scientific literacy (pp. 45-56). London: Routledge.

De Vos, W., Bulte, A. M. W. \& Pilot, A. (2002). Chemistry curricula for general education: Analysis and elements of a design. In J. K. Gilbert, R. Justi, O. de Jong \& J. Van Driel (Eds.), 
Chemical education: Towards research-based practice (pp. 101-124). Dordrecht, The Netherlands: Kluwer Academic Press.

EU (European Union). (2008). Key Competencies for lifelong learning: European reference framework. Luxembourg: Office for Official Publications of the European Communities. Retrieved from https://publications.europa.eu/en/publication-detail//publication/5719a044-b659-46de-b58b-606bc5b084c1

Fang, Y., \& Xu, D. (2018) (Eds.). An illustration to the general senior secondary school chemistry curriculum standards (the 2017 version). Beijing: Higher Education Press (in Chinese).

Fensham, J. P. (1997). School science and its problems with scientific literacy. In: Levinson, and Thomas, J. (Eds.), Science today: Problem or crisis (pp. 119-136). London: Routledge.

Goodson, I. (1993). School Subjects and Curriculum Change: Studies in Curriculum History (3rd ed.). Washington, D.C.: Falmer Press.

Gray, B. V. (1999). Guest Editorial: Science education in the developing world: Issues and considerations. Journal of Research in Science Teaching, 36(3), 261-268.

Grossman, P. L., \& Stodolsky, S. S. (1994) Considerations of content and the circumstances of secondary school teaching. In L. Darling-Hammond (Ed.), Review of Research in Education, 20(1), 179-221.

Grossman, P. L., \& Stodolsky, S. S. (1995) Content as context: the role of school subjects in secondary school teaching. Educational Researcher, 24 (8), 5-23.

Grossman, P. L., Wilson, S. M., \& Shulman, L. S. (1989). Teachers of substance: subject matter knowledge for teaching. In: M. C. Reynolds (Ed.), Knowledge Base for the Beginning Teacher (pp. 23-36). New York: Pergamon.

Liu, X. (2017). Science education reform policies. In L. L. Liang, X. Liu, \& G. W. Fulmer (Eds.), Chinese science education in the 21st century: Policy, Practice, and Research (pp. 1-4). Dordrecht: Springer.

MoE (Ministry of Education) (2001). An outline of curriculum reform of basic education. Xueke Jiaoyu, 2001(7), 1-5.

MoE (Ministry of Education) (2003). The general senior secondary school chemistry curriculum standards (the trial version). Beijing: People's Education Press (in Chinese).

MoE (Ministry of Education) (2014). Opinions on deepening curriculum reform and implementing the fundamental tasks of lide shuren. Official document (in Chinese).

MoE (Ministry of Education) (2018). The general senior secondary school chemistry curriculum standards (the 2017 version). Beijing: People's Education Press (in Chinese).

Moore, R. (2000). For knowledge: Tradition, progressivism and progress in educationreconstructing the curriculum debate. Cambridge Journal of Education, 30(1), 17-36. 
Pepper, D. (2011). Assessing key competencies across the curriculum-and Europe. European Journal of Education, 46(3), 335-353.

Posner, J. G. (1995). Analyzing the curriculum (2nd ed.). New York: McGraw-Hill.

Shulman, L. S. (1987). Knowledge and teaching: Foundations of the new reform. Harvard Educational Review, 57(1), 1-22.

Stacey, O., De Lazzari, G., Grayson, H., Griffin, H., Jones, E., Taylor, A., \& Thomas, D. (2018). The Globalization of Science Curricula. IEA Research for Education. Volume 3. International Association for the Evaluation of Educational Achievement.

Stengel, B. S. (1997) "Academic discipline" and "school subject": contestable curricular concepts. Journal of Curriculum Studies, 29(5), 585-602.

Voogt, J., \& Roblin, N. P. (2012). A comparative analysis of international frameworks for 21st century competencies: Implications for national curriculum policies. Journal of Curriculum Studies, 44(3), 299-321.

Wang, L. (2014) (Ed.). An international comparative study on science curriculum standards in secondary schools (the volume of chemistry). Beijing: Beijing Normal University Press (in Chinese).

Wang, L. \& Wei, R. (2018). The content and academic standards of high school chemistry curriculum for development of discipline core competencies: Interpretation of the 2017 Senior High School Chemistry Curriculum Standards. Chinese Journal of Chemical Education, 39 (9), 48-53 (in Chinese).

Wang, Y. Lavonen, J., \& Tirri, K. (2018). Aims for learning 21st century competencies in national primary science curricula in China and Finland. Eurasia Journal of Mathematics, Science \& Technology Education, 14 (6), 2081-2095.

Wang, Z. (2018a). The background of revising the Senior High School Chemistry Curriculum Standards. In: Y. Fang \& Xu, D. (2018) (Eds.). An illustration to the general senior secondary school chemistry curriculum standards (the 2017 version) (pp.1-35). Beijing: Higher Education Press (in Chinese).

Wang, Z. (2018b). From the research on core competence to the construction of the core competence of chemistry. In: Y. Fang \& Xu, D. (2018) (Eds.). An illustration to the general senior secondary school chemistry curriculum standards (the 2017 version) (pp.37-57). Beijing: Higher Education Press (in Chinese).

Wei, B. (2005). Science curriculum reform in post-compulsory education in the People's Republic of China: The case of senior secondary school chemistry curriculum. Science Education International, 16(4), 291-303.

Wei, B. (2012). In pursuit of professionalism in the field of chemistry education in China: The Story of Zhixin Liu. International Journal of Science Education, 34(13), 1971-1989. 
International Conference on Research in Education, Teaching and Learning

Paris, France| April 19-21, 2019

Wei, B. \& Thomas, G. P. (2005). Rationale and approaches for embedding scientific literacy into the new junior secondary school chemistry curriculum in the People's Republic of China. International Journal of Science Education, 27(12), 1477-1493.

Yao, J. X., \& Guo, Y. Y. (2018). Core competencies and scientific literacy: the recent reform of the school science curriculum in China. International Journal of Science Education, 40(15), 1913-1933. 